\title{
Prevalence and risk factors for khat use among youth students in Ethiopia: systematic review and meta-analysis, 2018
}

Wondale Getinet Alemu ${ }^{1 *}$, Tadele Amare Zeleke ${ }^{1}$, Wubet Worku Takele ${ }^{2}$ and Shegaye Shumet Mekonnen ${ }^{1}$

\begin{abstract}
Background: Khat use is a widely spreading public health problem affecting the most economically productive population areas in Ethiopia. Khat use among students has been linked with mental, physical, social, and psychological problems. Reliable prevalence has not been recognized because of varying published rates. The objective of this systematic review and meta-analysis is to synthesize evidence on the prevalence and potential risk factors of khat use in Ethiopia.
\end{abstract}

Methods: We found 284 studies of which 266 were removed due to duplication, irrelevant topics, and other reasons, respectively. All studies conducted in Ethiopia on khat chewing among students irrespective of time frame were included. Subsequently, 18 studies were used for synthesis of prevalence. Figures were extracted from published reports, and any lost information was requested from investigators. The quality of the included literature was evaluated by using the Newcastle-Ottawa Scale (NOS). Prevalence was pooled using random-effects meta-analyses. The presence of association was declared using P-values and an odds ratio with a corresponding $95 \% \mathrm{Cl}$.

Results: The pooled prevalence of khat use among students was $16.7 \%$ (13.7-19.7\%). In the subgroup analysis, the highest prevalence was observed in the Oromia region, at 21.1\% (15.5\%, 26.7\%), and an almost equal prevalence of $14.8 \%(10.6,18.9)$ and $14.3 \%(10.3,18.3)$ was observed in Amhara and the Southern Nation, Nationalities, and People's Region of Ethiopia, respectively. Being male (OR: $2.43(1.73,3.13))$, being a Muslim religion follower (OR: $2.22(1.6,2.8)$ ), being an alcohol user (OR: $2.3(1.5,3.0))$, khat use by a family member (OR: $1.8(1.4,2.2))$, peer pressure (OR: $4.4(3.1$, 5.6)), and being a cigarette smoker (OR: $8.5(5.3,11.7))$ were found to be risk factors for khat chewing.

Conclusions: Khat use is a common problem among students. Health promotion, awareness on effect of khat, set policy on khat and substance use on the male sex, Muslim religion, alcohol user, having a family-member khat user, peer pressure, and being a cigarette smoker as possible risk factors for khat use among students.

Limitations: Irrespective of time restriction, all studies conducted in Ethiopia are included and cross-sectional in nature. Protocol no. CRD-42017081886.

Keywords: Khat chewing, Khat use, Students, Ethiopia

*Correspondence: wondale22@gmail.com

${ }^{1}$ Department of Psychiatry, College of Medicine and Health Science, University of Gondar, Gondar, Ethiopia

Full list of author information is available at the end of the article

\section{Background}

Khat is a plant containing a natural psychoactive substance which is cultivated in East African as well as Arab lands [1]. Khat has different names in different countries, but "khat" remains the name widely used in studies [2]. The origin of khat is not known, but it is believed to be native to Ethiopia and was originally used there [3]. Khat 
contains the amphetamine-like substances cathine, cathinone, and methcathinone [4].

Khat has a stimulant effect on the body $[5,6]$. The fresh green leaves and young buds are chewed [7]. This stimulates both the peripheral and vital nervous system, causing, for instance, insomnia, alertness, anorexia, and increased respiration, body temperature, blood pressure, and heart rate [8]. The stimulant effect is mutually enhanced by caffeine use and cigarette smoking [9]. Khat use has appeared to be a male habit, but women practise it as well [10]. Users start chewing at an early age and develop an uncontrollable habit lasting throughout the lifespan [11]. It is practised based on local customs and traditions [12] and carried out in religious ceremonies $[13,14]$.

The World Health Organization report has shown that khat use causes dependency [15-19], predisposes the individual to myocardial infarction [20], ischemic heart disease [21], psychosis [22, 23], distress [24], premature ejaculation [25], unprotected sex [26], manic episodes $[27,28]$, oesophageal cancer [29], low birth weight and lactation problems [30], structural and functional brain changes [31, 32], and criminal activity [33].

Khat chewing is a familiar habit among students for staying alert, achieving higher concentration at work, socializing, and providing relaxation, relief from stress, and a desire to study for long hours [34-37].

Moreover, being male, having chewer friend(s), believing that chewing khat will boost performance, drinking alcohol, and having a family that cultivates khat were found to considerably increase the chewing practice [34, 38-40].

The literature includes studies conducted in Ethiopia among students. However, the literature shows a difference in prevalence and associated factors. Therefore, this systematic review and meta-analysis aim to estimate the pooled prevalence and associated factors of current use of khat chewing among students in Ethiopia.

\section{Methods}

PubMed/MEDLINE, Scopus, HINARI and EMBASE were searched for published studies. In addition, 10 pages were accessed using Google Scholar. All references in the relevant articles were reviewed in order to obtain other studies. Furthermore, for partial articles or those missing necessary information, the authors of the articles were contacted via email or other means of communication. For the PubMed search, the following terms were applied: 'khat chewing', 'khat use', 'chewing habit', 'determinant factors"', 'student', 'college students' and 'Ethiopia.' An advanced search was conducted using these terms with the options 'MeSH terms' and 'all fields' selected and including 'AND' and 'OR' Boolean operators as appropriate. The rest of the electronic databases were searched using database-specific subject headings linked with the terms and keywords used in PubMed. "Preferred Reporting Items for Systematic Reviews and Meta-Analyses (PRISMA)" guidelines used [41]. To show the procedures used for the screening and selection processes, a PRISMA flow diagram was used. The findings of this meta-analysis are presented here in with the aid of figures.

\section{Review and meta-analysis registration}

This systematic review and meta-analysis were registered at the International Prospective Register of Systematic Reviews. The following represents the registration number: CRD-42017081886.

\section{Eligibility criteria}

Three investigators (WG, TA and WW) independently screened the selected articles using their titles and abstracts before retrieving the full-text papers. We use pre-specified inclusion criteria to screen the full-text articles. Disagreements between the investigators were discussed during a consensus meeting with a fourth reviewer (SS) in order to select the studies to be included in the systematic review and meta-analysis.

\section{Inclusion criteria}

- Cross-sectional studies.

- Studies on khat chewing among students.

- Studies published in English.

- Studies reporting on the prevalence and/or determinants of khat chewing.

- Studies conducted in Ethiopia.

\section{Exclusion criteria}

- Editorials, letters, reviews, commentaries and interventional studies.

- Studies without access to the full data even after contacting the author(s).

- Duplicate studies.

\section{Data extraction}

All the articles accessed using the databases and search engines were exported to EndNote (version 6), and we excluded duplicate articles. The remaining articles were evaluated based on the topic, language and study area. Next, studies conducted outside of Ethiopia, those not published in English and those on irrelevant topics were excluded. There were no time restrictions among the 
included studies. Finally, the abstracts and full text of the remaining articles were reviewed.

\section{Outcome variable}

Current khat use is defined as the proportion of students who are chewing for different purposes within 3 months of prior to data collection.

\section{Data synthesis and quality assessment}

After extracting and documenting the data in a Microsoft Excel spreadsheet, we exported it to Stata (version 14) for further analysis. All the analyses were conducted using Comprehensive Meta analysis software (version 3) [42]. The overall pooled prevalence of khat chewing was estimated using a random-effects meta-analysis [43]. First, using a fixed-effects model, heterogeneity among the studies was determined. A Q test and an $\mathrm{I}^{2}$ heterogeneity test [43] were used to declare heterogeneity at $p<0.05$. The prevalence of statistical heterogeneity between the studies was assessed using $\mathrm{I}^{2}$ statistics, with $25 \%, 50 \%$ and $75 \%$ representing low, medium and high heterogeneity, respectively [44]. The quality of the included studies was evaluated using the Newcastle-Ottawa Scale [45] and tested based on sample size and representativeness, comparability between participants, ascertainment of khat chewing and statistical quality. To test the agreement between the three reviewers, the actual agreement and agreement beyond chance (unweighted kappa) were used. The values of reviewers' result $0,0.01-0.20,0.21-$ $0.40,0.41-0.60,0.61-0.80$, and $0.81-1.00$ were used to represent poor, slight, fair, moderate, substantial, and almost perfect agreements, respectively [46]. A randomeffects model was used in the analysis. Meta-regression was conducted to explore the probable source of heterogeneity. A leave-one-out sensitivity analysis was also conducted to assess which studies majorly impacted between-study heterogeneity. A funnel plot and Egger's regression test were used to measure publication bias.

\section{Results}

\section{Search outcomes}

The systematic literature search generated a total of 284 articles. In total, 55 were duplicated and 167 were irrelevant, and, as such, these were excluded. In addition, 44 were excluded (not measure outcome, measure not current use). The remaining 18 articles were used to determine the pooled prevalence of khat chewing in Ethiopia. All 18 articles were cross-sectional studies (Fig. 1).

All the included studies were conducted in Ethiopia (Table 1). Finally, the levels of agreements between the reviewers about the levels of bias for studies included in this meta-analysis we got from moderate to almost perfect (Kappa statistic range 0.60-1) (Table 2).
Pooled prevalence of khat chewing among students

The pooled prevalence of khat chewing in Ethiopia was 16.7\% (13.7-19.7: $\mathrm{I}^{2}=63.8 \%, p \leq 0.001$ ) (Fig. 2).

In the random-effects model, the subgroup analysis by setting on high school and university is different which is $14.61 \%\left(11.09,18.13: \mathrm{I}^{2}=11.9 \%, p=0.338\right)$ and $17.56 \%$ (13.52, 21.61: $\mathrm{I}^{2}=71.6 \%, p=0.001$ ), respectively (Fig. 3).

By region showed that the highest prevalence of khat chewing was observed in the Oromia Region (OR: 21.1 $(15.5,26.7))$. A comparable prevalence was observed in the Amhara Region (OR: $14.8(10.6,18.9))$ and the southern Nation Nationality people of Ethiopia (OR: 14.3 (10.3, 18.3)) (Fig. 4).

\section{Publication bias}

There was no evidence of bias, as observed in the funnel plot. An Egger's regression test confirmed this $(p=0.53)$ (Fig. 5).

\section{Factors associated with khat use}

Khat use is common among high school, college and university students. There are many risk factors, but just we include those reported in more than one study. Being male is more likely to chew khat than females (OR: 2.43 $(1.73,3.13)$. In addition, khat chewing is predominantly practised by Muslims (OR: $2.22(1.6,2.8)$. Students with a family member who had a history of khat use or who currently uses khat are more likely to chew khat than students without such a family member (OR: $1.8(1.4,2.2)$.

\section{Discussion}

The objectives of this systematic review and meta-analysis were to assess the prevalence and associated factors of khat use among young students in Ethiopia. Young students who are habitual khat users believe that its use boosts alertness, concentration, imaginative abilities, and improves communication skills. To the best of our knowledge, this systematic review and meta-analysis is the first of its kind, assessing the pooled prevalence and factors that have an effect on the habitual use of khat among young students in Ethiopia. The overall pooled prevalence of khat use was found to be $16.7 \%$ (13.7-19.7). The pooled prevalence of Khat use was found to be different across regions; it was highest in the Oromia region, $21.10 \%(15.52,26.68)$, and we found a similar prevalence in the Amhara and SNNPs regions, $14.78(10.6,18.9)$ and $14.3(10.3,18.3)$, respectively (figure-3). Clearly illustrated above, the subgroup analysis demonstrated that the pooled prevalence of khat use among young students is slightly different across different regions of Ethiopia. The possible reason for these variations could be environmental, religious, and/or 


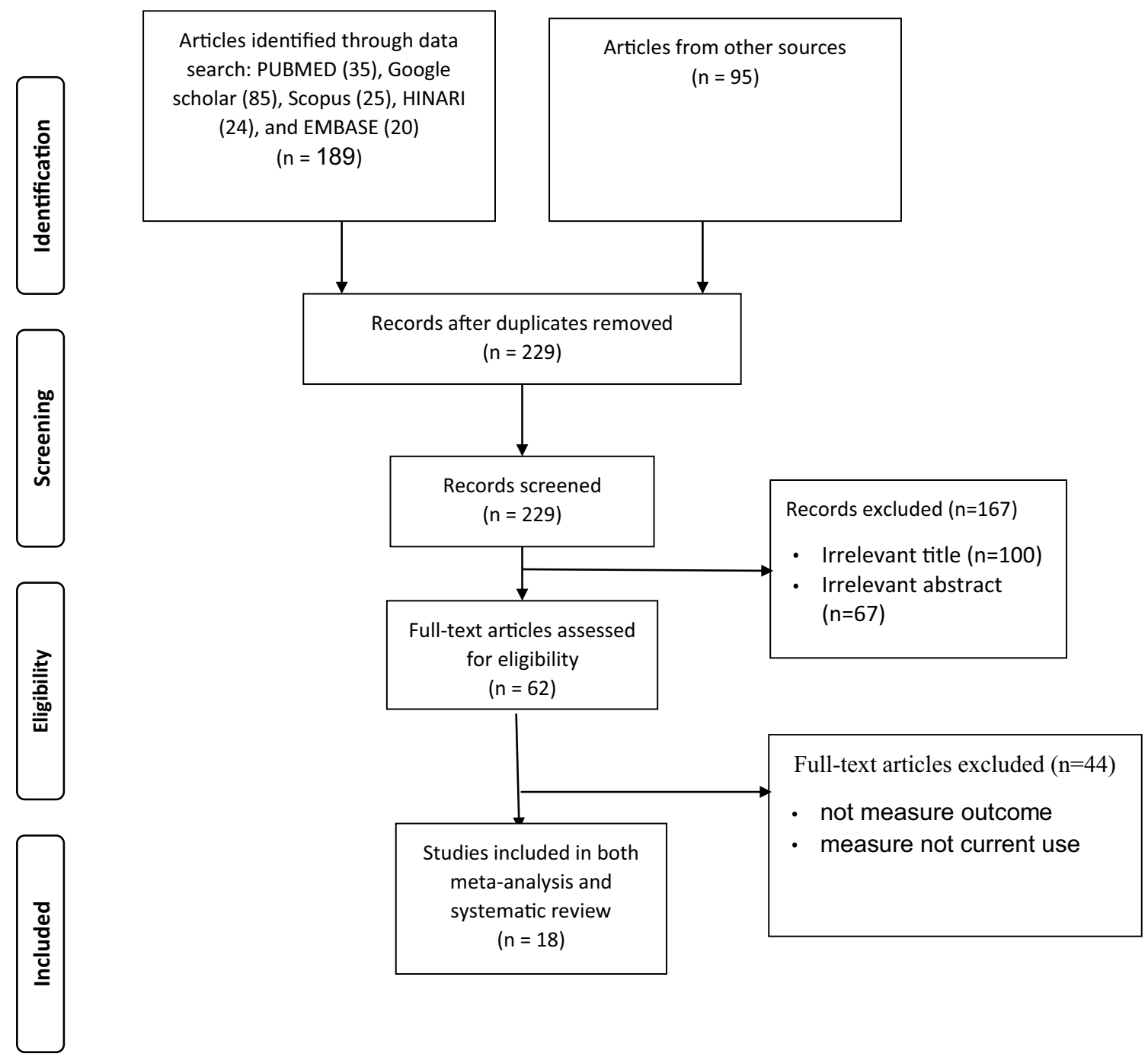

Fig. 1 Flowchart describes the selection of studies for the systematic review and meta-analysis of prevalence and risk factors of khat chewing among students in Ethiopia, 2018

cultural differences across the regions. For example, people residing in the Oromia region are Muslim followers. In addition to this, the higher prevalence of khat chewing in this region could be explained by the differences in settings across regions, such as access to khat and factors outside the university and high school environment.

A meta-analysis study previously completed on University students found that $23.22 \%$ (95\% CI $19.5,27.0 \%$ ) of these students were chewers, which is a bit higher than our findings [43]. This discrepancy might be due to differences in study population, while ours considered young students on high school and university, the former one focused on university students, these students couldn't afford to buy the khat and they might not use.
Multiple factors have contributed to young students to be khat users. Being male, younger age, religion, ethnicity, khat use by family, family history of other substances use, living condition, peer pressure, other psychoactive substance use, having a family that cultivates khat, perceive khat use boosts performance, increased class workload, residency, having suicidal ideation, having ever had a sexual contact were found to be the most important associated factors.

Gender of students continued to be a significant factor affecting students' behaviour. Being male sex had a significant role to be user as compared to females. This finding is line with studies conducted in Ethiopia [2, 36, 47-51]. This significant difference between male and female may be justified as; females are less exposed to chewing 
Table 1 Descriptive summary of 18 studies reporting the prevalence and associated factors of khat chewing among students in Ethiopia included in the systematic review and meta-analysis, 2018

\begin{tabular}{|c|c|c|c|c|c|c|c|}
\hline Author & Year & Region & Study area & Sample size & $\begin{array}{l}\text { Response } \\
\text { rate }(\%)\end{array}$ & The objective of the study & Prevalence $(95 \% \mathrm{Cl})$ \\
\hline Abdeta $T$ & 2017 & Oromia & Jimma University & 651 & 95.1 & $\begin{array}{l}\text { Prevalence, withdrawal symptoms and } \\
\text { associated factors of khat chewing among } \\
\text { students at Jimma University in Ethiopia }\end{array}$ & $23.9(14.50,33.30)$ \\
\hline Ayana A & 2004 & Oromia & Jimma University & 500 & 97.1 & $\begin{array}{l}\text { Khat (Catha edulis Forsk) chewing, sociode- } \\
\text { mographic description and its effect on } \\
\text { academic performance, Jimma University } \\
\text { students }\end{array}$ & $24.8(15.28,34.30)$ \\
\hline Reda A & 2012 & Oromia & Harar Town & 1890 & 91.1 & $\begin{array}{l}\text { Prevalence and determinants of khat (Catha } \\
\text { edulis) chewing among high school stu- } \\
\text { dents in eastern Ethiopia: a cross-sectional } \\
\text { study }\end{array}$ & $24.2(14.62,33.78)$ \\
\hline Dires E & 2016 & Oromia & Jimma town & 296 & 100 & $\begin{array}{l}\text { Factors associated with khat chewing } \\
\text { among high school Students in Jimma } \\
\text { Town Southwest Ethiopia }\end{array}$ & $14.2(6.99,21.41)$ \\
\hline Astatkie A & 2015 & SNNPR & Hawassa University & 1255 & 97.3 & $\begin{array}{l}\text { Prevalence of and factors associated with } \\
\text { regular khat chewing among university } \\
\text { students in Ethiopia }\end{array}$ & $10.5(4.18,16.82)$ \\
\hline Kassa A & 2011 & SNNPR & Hawassa University & 590 & 94.5 & $\begin{array}{l}\text { Determinants of alcohol use and khat chew- } \\
\text { ing among Hawassa University students, } \\
\text { Ethiopia: a cross-sectional study }\end{array}$ & $16.3(8.50,24.10)$ \\
\hline Kassa A & 2017 & SNNPR & Sidama zone & 1577 & 95.3 & $\begin{array}{l}\text { Prevalence of khat chewing and its effect on } \\
\text { academic performance in Sidama zone, } \\
\text { Southern Ethiopia }\end{array}$ & $13.0(5.96,20.04)$ \\
\hline Kassa A & 2014 & SNNPR & Hawassa University & 586 & 99.3 & $\begin{array}{l}\text { Prevalence and factors determining } \\
\text { psychoactive substance (PAS) use among } \\
\text { Hawassa University (HU) undergraduate } \\
\text { students, Hawassa Ethiopia }\end{array}$ & $20.3(11.62,28.98)$ \\
\hline Gebreslassie M & 2013 & Tigray & Axum University & 764 & 98.7 & $\begin{array}{l}\text { Psychoactive substances use and associated } \\
\text { factors among Axum University students, } \\
\text { Axum Town, North Ethiopia }\end{array}$ & $27.9(17.74,38.06)$ \\
\hline Gebrehanna E & 2014 & Amhara & Bahir Dar University & 3268 & 77.5 & $\begin{array}{l}\text { Khat chewing among Ethiopian University } \\
\text { Students - a growing concern }\end{array}$ & $12.7(5.73,19.67)$ \\
\hline Teni FS & 2015 & Amhara & Gonder university & 424 & 94.3 & $\begin{array}{l}\text { Prevalence, reasons, and perceived effects } \\
\text { of khat chewing among students of a } \\
\text { college in Gondar Town, Northwestern } \\
\text { Ethiopia: a cross-sectional study }\end{array}$ & $32.5(21.76,43.24)$ \\
\hline Zein ZA & 1998 & Amhara & Gonder university & 479 & 98.8 & $\begin{array}{l}\text { Polydrug abuse among Ethiopian university } \\
\text { students with particular reference to khat } \\
\text { (Catha edulis) }\end{array}$ & $22.3(13.26,31.34)$ \\
\hline Bizuayehu G & 2009 & Amhara & Gonder & 397 & 98.5 & $\begin{array}{l}\text { Prevalence, factors and consequences } \\
\text { of khat chewing among high school } \\
\text { students of Gondar Town, Northwestern } \\
\text { Ethiopia }\end{array}$ & $12.6(5.75,19.45)$ \\
\hline Aklilu S & 2013 & Amhara & Gonder university & 302 & 97.4 & $\begin{array}{l}\text { Prevalence and associated factors of khat } \\
\text { chewing among Atse Fasil Campus Stu- } \\
\text { dents, University of Gondar, North West } \\
\text { Ethiopia June }\end{array}$ & $6.9(1.84,12.06)$ \\
\hline Berihun AD & 2015 & Amhara & Gonder University & 872 & 95.8 & $\begin{array}{l}\text { Khat use and Its determinants among } \\
\text { University students in Northwest Ethiopia: } \\
\text { a multivariable analysis }\end{array}$ & $13.6(6.43,20.77)$ \\
\hline Lakew A & 2014 & Amhara & Ataye & 332 & 88 & $\begin{array}{l}\text { Prevalence of Catha edulis (khat) chewing } \\
\text { and Its associated factors among Ataye } \\
\text { Secondary School Students in Northern } \\
\text { Showa, Ethiopia }\end{array}$ & $13.3(6.26,20.24)$ \\
\hline Adere A & 2017 & Amhara & Woldia university & 730 & 89.7 & $\begin{array}{l}\text { Determinants of psychoactive substances } \\
\text { use among Woldia University students in } \\
\text { Northeastern Ethiopia }\end{array}$ & $10.4(4.12,16.68)$ \\
\hline
\end{tabular}


Table 1 (continued)

\begin{tabular}{|c|c|c|c|c|c|c|c|}
\hline Author & Year & Region & Study area & Sample size & $\begin{array}{l}\text { Response } \\
\text { rate }(\%)\end{array}$ & The objective of the study & Prevalence $(95 \% \mathrm{Cl})$ \\
\hline Yegazew K & 2002 & Amhara & Gonder university & 1258 & 87.7 & $\begin{array}{l}\text { Cigarette smoking and khat chewing } \\
\text { among college students in North West } \\
\text { Ethiopia }\end{array}$ & $17.5(9.36,25.64)$ \\
\hline
\end{tabular}

Table 2 The quality and agreed level of bias and level of agreement on the methodological qualities of included studies in a meta-analysis based on sampling, outcome, response rate and method of analysis

\begin{tabular}{|c|c|c|c|c|}
\hline Study & Percentage of agreement & Kappa value & Level of agreement & $\begin{array}{l}\text { Nos quality (score } \\
\text { on } 0 \text { to } 9 \text { scale) }\end{array}$ \\
\hline Abdeta T (2017) & 100 & 1 & Almost perfect & 8 \\
\hline Ayana A (2004) & 100 & 1 & Almost perfect & 9 \\
\hline Reda A (2012) & 100 & 1 & Almost perfect & 8 \\
\hline Dires E (2016) & 100 & 1 & Almost perfect & 8 \\
\hline Astatkie A (2015) & 100 & 1 & Almost perfect & 8 \\
\hline Kassa A (2016) & 100 & 1 & Almost perfect & 9 \\
\hline Kassa A (2017) & 100 & 1 & Almost perfect & 9 \\
\hline Kassa A (2014) & 100 & 1 & Almost perfect & 9 \\
\hline Gebreslassie M (2013) & 100 & 1 & Almost perfect & 9 \\
\hline Gebrehanna E (2014) & 100 & 1 & Almost perfect & 8 \\
\hline Teni FS (2015) & 75 & 0.60 & Moderate & 7 \\
\hline Zein ZA (1998) & 75 & 0.60 & Moderate & 7 \\
\hline Bizuayehu G (2009) & 100 & 1 & Almost perfect & 9 \\
\hline Aklilu S (2013) & 100 & 1 & Almost perfect & 8 \\
\hline Berihun AD (2015) & 100 & 1 & Almost perfect & 9 \\
\hline Lakew A (2014) & 100 & 1 & Almost perfect & 8 \\
\hline Adere A (2017) & 100 & 1 & Almost perfect & 8 \\
\hline Yegazew K (2002) & 100 & 1 & Almost perfect & 9 \\
\hline
\end{tabular}

practice than males. Moreover, we found that being Muslim by religion had a significant role to be user than others $[2,36,41,43,51,52]$.

Having chewer friends was strong predictor of chewing which is similar to other studies [2, 41, 43, 45, 49, 50, 53], khat use by family member was associated with increased odds of use among participants. This finding was similar with studies conducted on substance abuse [2, 36, 48, 49]. The possible cause for the association may be because of shared influence and peer pressure.

Furthermore, in this review, it has been observed that other substance use is common among study participants. Who had ever drunk alcohol and ever smoked cigarette were more likely to practise chewing as compared to no alcohol and cigarette users. This finding is supported by $\mathrm{r}$ studies conducted, ever drunk alcohol [52, $54]$, and smoking cigarette $[43,48,50,52,54]$. These studies reported that history of alcohol consumptions and cigarette smoking was positively associated with chewing. This finding provides evidence on the prevalence of khat use on Ethiopian students with relevant data. Measures to reduce the use of khat should be taken and these should be considered as priority areas: awareness, family contribution, prevention and early intervention.

\section{Conclusions}

Khat use is prevalent among high school, college and university students. The prevalence of khat use appeared to be high. Particular attention should be given to male gender, Muslims religion follower, alcohol users, having family member khat user, peer pressure, being cigarette smoker. There is a need for early intervention that targets high school, college, and university students to reduce the health, financial and social consequences of khat use.

\section{Limitations of the study}

The limitation was that only English articles were considered to conduct this review. In addition, all of the studies included in this review were cross-sectional 


$$
\text { Study }
$$

$$
\text { ID }
$$

Abdeta T (2016)

Adere A (2015)

Astatkie A (2014)

Ayana A (2002)

Gebrehanna E (2014)

Gebreslassie M (2012)

Kassa A (2015)

Reda A (2010)

Teni F (2009)

Zein Z (1988)

Bizuayehu G (2009)

Aklilu S (2013)

Berihun A (2014)

Awoke L (2014)

Kassa A (2011)

Yegazew K (2001)

Dires E (2016)

Kassa A (2014)

Overall (I-squared $=63.8 \%, p \leq 0.001)$

NOTE: Weights are from random effects analysis

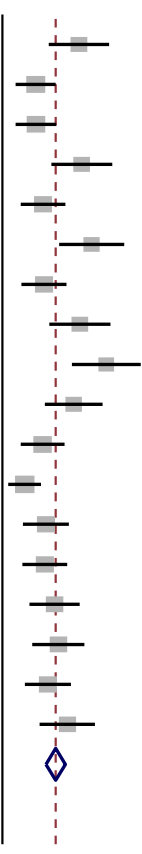

$\%$

ES $(95 \% \mathrm{Cl}) \quad$ Weight

$23.90(14.50,33.30) 4.78$

$10.40(4.12,16.68) \quad 6.45$

$10.50(4.18,16.82) \quad 6.42$

$24.79(15.28,34.30) 4.73$

$12.70(5.73,19.67) \quad 6.05$

$27.90(17.74,38.06) \quad 4.43$

$13.00(5.96,20.04) \quad 6.02$

$24.20(14.62,33.78) 4.69$

$32.50(21.76,43.24) \quad 4.18$

$22.30(13.26,31.34) 4.95$

$12.60(5.75,19.45) \quad 6.12$

$6.95(1.84,12.06) \quad 7.13$

$13.60(6.43,20.77) \quad 5.94$

$13.25(6.26,20.24) \quad 6.04$

$16.30(8.50,24.10) \quad 5.59$

$17.50(9.36,25.64) \quad 5.41$

$14.20(6.99,21.41) \quad 5.92$

$20.30(11.62,28.98) 5.13$

$16.66(13.66,19.67) \quad 100.00$

Fig. 2 Forest plot of pooled prevalence of khat chewing in Ethiopian students 2018 ( $n=18)$

\section{Study \\ ID}

\section{UST}

Abdeta T (2016)

Adere A (2015)

Astatkie A (2014)

Ayana A (2002)

Gebrehanna E (2014)

Gebreslassie M (2012)

Teni F (2009)

Zein Z (1988)

Aklilu S (2013)

Berihun A (2014)

Kassa A (2011)

Yegazew K (2001)

Kassa A (2014)

Subtotal (I-squared $=71.6 \%, p=0.001)$

High school

Kassa A (2015)

Reda A (2010)

Bizuayehu G (2009)

Awoke L (2014)

Dires E (2016)

Subtotal $($ I-squared $=11.9 \%, p=0.338)$

Overall $($ I-squared $=63.8 \%, p=0.001)$

NOTE: Weights are from random effects analysis
$\%$

ES $(95 \% \mathrm{Cl}) \quad$ Weight

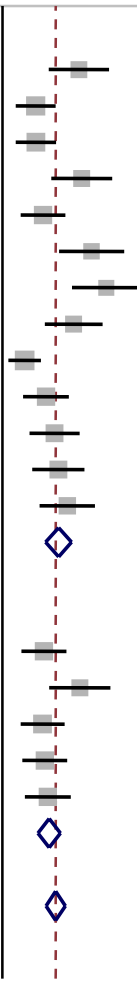

$23.90(14.50,33.30) \quad 4.78$

$10.40(4.12,16.68) \quad 6.45$

$10.50(4.18,16.82) \quad 6.42$

$24.79(15.28,34.30) \quad 4.73$

$12.70(5.73,19.67) \quad 6.05$

$27.90(17.74,38.06) \quad 4.43$

$32.50(21.76,43.24) \quad 4.18$

$22.30(13.26,31.34) \quad 4.95$

$6.95(1.84,12.06) \quad 7.13$

$13.60(6.43,20.77) \quad 5.94$

$16.30(8.50,24.10) \quad 5.59$

$17.50(9.36,25.64) \quad 5.41$

$20.30(11.62,28.98) \quad 5.13$

$17.56(13.52,21.61) \quad 71.20$

$13.00(5.96,20.04) \quad 6.02$

$24.20(14.62,33.78) \quad 4.69$

$12.60(5.75,19.45) \quad 6.12$

$13.25(6.26,20.24) \quad 6.04$

$14.20(6.99,21.41) \quad 5.92$

$14.61(11.09,18.13) \quad 28.80$

$16.66(13.66,19.67) \quad 100.00$

Fig. 3 Subgroup analysis on prevalence of khat chewing among high school and university students $2018(n=18)$ 


\begin{tabular}{|c|c|c|c|}
\hline \multirow{2}{*}{\multicolumn{2}{|c|}{ Study }} & \multirow[b]{2}{*}{$\mathrm{ES}(95 \% \mathrm{Cl})$} & \multirow{2}{*}{$\begin{array}{l}\% \\
\text { Weight }\end{array}$} \\
\hline & & & \\
\hline Oromiya & & & \\
\hline Abdeta T (2016) & $\frac{1}{1+2}$ & $23.90(14.50,33.30)$ & 4.78 \\
\hline Ayana A (2002) & $\frac{1}{1}$ & $24.79(15.28,34.30)$ & 4.73 \\
\hline Reda A (2010) & + & $24.20(14.62,33.78)$ & 4.69 \\
\hline Dires E (2016) & + & $14.20(6.99,21.41)$ & 5.92 \\
\hline Subtotal $(1-$ squared $=37.4 \%, p=0.188)$ & & $21.10(15.52,26.68)$ & 20.12 \\
\hline \multicolumn{4}{|l|}{ Amhara } \\
\hline Adere A (2015) & - & $10.40(4.12,16.68)$ & 6.45 \\
\hline Gebrehanna E (2014) & + & $12.70(5.73,19.67)$ & 6.05 \\
\hline Teni F (2009) & - & $32.50(21.76,43.24)$ & 4.18 \\
\hline Zein Z (1988) & & $22.30(13.26,31.34)$ & 4.95 \\
\hline Bizuayehu G (2009) & 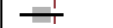 & $12.60(5.75,19.45)$ & 6.12 \\
\hline Aklilu S (2013) & $=1$ & $6.95(1.84,12.06)$ & 7.13 \\
\hline Berihun A (2014) & + & $13.60(6.43,20.77)$ & 5.94 \\
\hline Awoke L (2014) & $\frac{1}{1-1}$ & $13.25(6.26,20.24)$ & 6.04 \\
\hline Yegazew K (2001) & 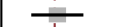 & $17.50(9.36,25.64)$ & 5.41 \\
\hline Subtotal (I-squared $=66.6 \%, p=0.002)$ & $\diamond$ & $14.78(10.62,18.94)$ & 52.29 \\
\hline \multirow{2}{*}{\multicolumn{4}{|c|}{ SNNPRs }} \\
\hline & & & \\
\hline Astatkie A (2014) & - & $10.50(4.18,16.82)$ & 6.42 \\
\hline Kassa A (2015) & + & $13.00(5.96,20.04)$ & 6.02 \\
\hline Kassa A (2011) & I & $16.30(8.50,24.10)$ & 5.59 \\
\hline Kassa A (2014) & $\underline{1}$ & $20.30(11.62,28.98)$ & \\
\hline Subtotal $($ I-squared $=16.7 \%, p=0.308)$ & $\diamond$ & $14.32(10.30,18.35)$ & 23.16 \\
\hline . & & & \\
\hline \multicolumn{4}{|l|}{ Tigray } \\
\hline Gebreslassie M (2012) & & $27.90(17.74,38.06)$ & 4.43 \\
\hline Subtotal (I-squared $=\%, \mathrm{p} \leq 0001$ ) & & $27.90(17.74,38.06)$ & 4.43 \\
\hline Overall (I-squared $=63.8 \%, p \leq 0.001$ ) & $\diamond$ & $16.66(13.66,19.67)$ & 100.00 \\
\hline NOTE: Weights are from random effects analysis & & & \\
\hline
\end{tabular}

Fig. 4 Subgroup prevalence of khat chewing in Ethiopian students, $2018(n=18)$

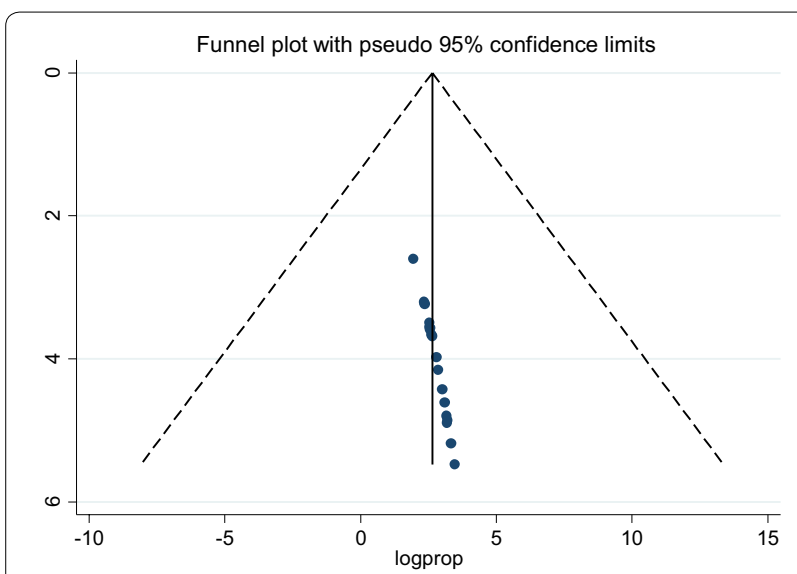

Fig. 5 Funnel plot showing publication bias of prevalence studies among students, a systematic review and meta-analysis, Ethiopia, 2018

in nature, as a result the outcome variable might be affected by confounding variables.

\section{Abbreviations}

AOR: Adjusted odds ratio; WHO: World Health Organization; COR: Crude odds ratio; Cl: Confidence interval; OR: Odds; SPSS: Statistical Package for Social Science; MOOSE: Meta-analysis of observational studies.

\section{Acknowledgments}

We thank the authors for providing additional data. We would like to thank our friends for their tireless gratitude and honest support even though we were preparing this review.

\section{Authors' contributions}

WGA had a primary role in the conceptualization, data review, data extraction, data analysis, in the write-up and editing of this manuscript. TAZ had a role in data review, data extraction, in the write-up and editing of this manuscript. WWT had a role in data review, data extraction, in the write-up and editing of this manuscript. SSM had a role in data review, data extraction, in the writeup and editing of this manuscript. All authors read and approved the final manuscript.

\section{Funding}

Not applicable.

\section{Availability of data and materials}

Not applicable.

\section{Ethics approval and consent to participate}

This review of previously reported studies required no ethical approval or additional consent from participants.

\section{Consent for publication}

Not applicable.

\section{Competing interests}

The authors declared that they have no competing interests.

\section{Author details}

${ }^{1}$ Department of Psychiatry, College of Medicine and Health Science, University of Gondar, Gondar, Ethiopia. ${ }^{2}$ Department of Community Health Nursing, School of Nursing, College of Medicine and Health Sciences, University of Gondar, Gondar, Ethiopia. 
Received: 30 May 2019 Accepted: 21 February 2020

Published online: 09 March 2020

\section{References}

1. Berhanu M, Aregash E, Alyi M. Socio-economic impact of Khat in Mana District, Jimma Zone, South Western Ethiopia. Discourse J Agric Food Sci. 2014;2(2):21-322.

2. Reda AA, Moges A, Biadgilign S, Wondmagegn BY. Prevalence and determinants of khat (Catha edulis) chewing among high school students in eastern Ethiopia: a cross-sectional study. PLoS ONE. 2012;7(3):e33946.

3. Nencinp I, Rassmsci G, Botana A, Asseyar F. Khat chewing spread to the Somali community in Rome. Drug Alcohol Depend. 1988;23(4):255.

4. Aseffa M. Socio-economic aspects of khat in the Harrarghe administrative region. Antananarivo, Madagascar: Ethiopia. In: Proceedings of the international conference on Khat. 1983.

5. Brenneisen RFH, Koelbing U, Geisshusler S, Kalix P. Amphetamine-like effects in humans of the khat alkaloid cathinone. Br J Clin Pharmacol. 1990;30(6):825-8

6. Cox G, Rampes H. Adverse effects of Khat chewing: a review. Journal of continuing professional development. Adv Psychiatr Treat. 2003;9:456-63.

7. Ezekiel G. Khat in the Horn of Africa: Historical perspectives and current trends. J Ethno Pharmacol. 2010;132(3):607-14

8. Kalix P. Catha edulis, a plant that has amphetamine effects. Pharm World Sci. 1996;18:69-73

9. Dhaifalah I, Santavy J. Khat habit and its health effect. A natural amphetamine. Biomed Pap Med Fac Univ Palacky Olomouc Czech Repub. 2004;148(1):11-5

10. Zein ZA. Polydrug abuse among Ethiopian university students with particular reference to khat (Catha edulis). J Trop Med Hyg. 1988;91(2):71-5.

11. Kennedy JG. The flower of paradise: the institutionalized use of the drug qat in North Yemen. Dordrecht: D Reidel Publications; 1987. p. 98-100.

12. Kalix P, Braenden O. Pharmacological aspects of the chewing of khat leaves. Pharmacol Rev. 1985;37:149-64.

13. Adam F, Hasselot N. Khat: from traditional usage to risk of drug addiction. Med Trop Adams Mars. 1994;25(2):141-4.

14. Banjaw M, Schmidt W. Behavioural sensitisation following repeated intermittent oral administration of Catha edulis in rats. Behav Brain Res. 2005;156:181-9.

15. Banjaw M, Schmidt W. Catha edulis extract and its active principle cathinone induce ipsilateral rotation in unilaterally lesioned rats. Behav Pharmacol. 2006:17:615-20

16. Giannini AJ, Miller MS, Turner CE. Treatment of khat addition. J Subst Abuse Treat. 1992:9:379-82.

17. Kalix P. Khat: scientific knowledge and policy issues. Br J Addict. 1987;82:47-53.

18. Elmai. Khat consumption and problems in Somalia. In: Proceedings of the international conference on Khat, Antananarivo, Madagascar. 1983.

19. Morghemm M, Rufatm I. Cultivation and chewing of khat in the Yemen Arab Republic. In: Proceedings of the international conference on Khat, Antananarivo, Madagascar. 1983.

20. Getajiu A, Krikoriaand N. The economic and social importance of khat and suggested research and services. In: Proceedings of the international conference on Khat, Antananarivo, Madagascar. 1983.

21. Alhegami MA. Effects of Khat (catha edulis) on some blood contents and the tissues of digestive system of rabbits. [dissertation] Sana'a (Yemen): Sana'a University. 2001.

22. Singh BN. Newer concepts in pathogenesis of myocardial Ischemia: Implications for evaluation of antianginal therapy. Drugs. 1986:32:1-14

23. Gough SP, Cookson IP. Khat-induced schizophreniform psychosis in UK. Lancet. 1984;8374:455.

24. Giannini AJ, Castellani S. A manic-like psychosis due to khat (Catha edulis Forsk). Toxicol Clin Toxicol. 1982;19:455-9

25. Newton T, Kalechstein A, Duran S, Vansluis N, Ling W. Methamphetamine abstinence syndrome: Preliminary findings. Am J Addict. 2004;13(3):248-55.

26. Malaju MT, Asale GA. Association of Khat and alcohol use with HIV infection and age at first sexual initiation among youths visiting HIV testing and counseling centers in Gamo-Gofa Zone, South West Ethiopia. BMC Int Health Hum Rights. 2013;13:10.

27. Kebede D, Alem A, Mitike G, Enquselassie F, Berhane F, Abebe Y, et al. Khat and alcohol use and risky sex behaviour among in-school and out-ofschool youth in Ethiopia. BMC Public Health. 2005;5:109.

28. Alem A, Shibre T. Khat induced psychosis and its medico-legal implication: A case report. Ethiop Med J. 1997:35(2):137-9.

29. Odenwald M, Neuner F, Schauer M, Elbert T, Catani C, Lingenfelder RB. Khat use as risk factor for psychotic disorders: a cross-sectional and casecontrol study in Somalia. BMC Med. 2005;3:5.

30. Balint E, Falkay G, Balint G. Khat-a controversial plant. Wiener klinische Wochenschrift Midd Eur J Med. 2009:121:604-14.

31. Mwenda J, Arimi M, Kyama M, Langat D. Effects of khat (catha edulis) consumption on reproductive function. A review. East Afr Med J. 2003;80(6):318-23.

32. Yucel M, Lubman D. Neurocognitive and neuroimaging evidence of behavioural dysregulation in human drug addiction: implications for diagnosis, treatment and prevention. Drug Alcohol Rev. 2007:26:33-9.

33. Yucel M, Lubman D, Harrison B, Fornito A, Allen N, Wellard R, et al. A combined spectroscopic and functional MRI investigation of the dorsal anterior cingulated region in opiate addiction. Mol Psychiatr. 2007;12:691-702.

34. Al-Motarreb A, Al-Habori M, Broadley KJ. Khat chewing, cardiovascular diseases and other internal medical problems. J Ethnopharmacol. 2010;132(3):540-8.

35. Meressa K, Mossie A, Gelaw Y. Effect of substance use on academic achievement of health officer and medical students of Jimma University Southwest Ethiopia. Ethiop J Health Sci. 2009:19:3.

36. Kebede $Y$. Cigarette smoking and khat chewing among university instructors in Ethiopia. East Afr Med J. 2002;79(5):274-8

37. Basunaid S, van Dongen M, Cleophas TJ. Khat abuse in Yemen: a populationbased survey. Clin Res Regul Affairs. 2008;25(2):87-92.

38. Al Khader NL, Darwish H. Prevalence of cigarette smoking and khat chewing among Aden university medical students and their relationship to BP and body mass index. Saudi J Kid Dis Transpl. 2009;20(5):862.

39. Deressa W, Azazh A. Substance use and its predictors among undergraduate medical students of Addis Ababa University in Ethiopia. BMC Public Health. 2011;11(1):660.

40. Kassa A, Loha E, Esaiyas A. Prevalence of khat chewing and its effect on academic performance in Sidama zone Southern Ethiopia. Afr Health Sci. 2017;17(1):175-85.

41. Moher D, Liberati A, Tetzlaff J, Altman DG, Group P. Preferred reporting items for systematic reviews and meta-analyses: the PRISMA statement. PLoS Med. 2009;6(7):e1000097.

42. Borenstein M, Hedges L, Higgins J, Rothstein H. Comprehensive metaanalysis version 2. Englewood: Biostat; 2005. p. 104.

43. Gebrie A, Alebel A, Zegeye A, Tesfaye B. Prevalence and predictors of khat chewing among Ethiopian university students: A systematic review and meta-analysis. PloS ONE. 2018;13(4):e0195718.

44. Higgins JP, Thompson SG, Deeks JJ, Altman DG. Measuring inconsistency in meta-analyses. BMJ. 2003;327(7414):557.

45. Stang A. Critical evaluation of the Newcastle-Ottawa scale for the assessment of the quality of nonrandomized studies in meta-analyses. Eur J Epidemiol. 2010:25(9):603-5.

46. Landis JR, Koch GG. The measurement of observer agreement for categorical data. Biometrics. 1977:33:159-74.

47. Dires E, Soboka M, Kerebih H, Feyissa GT. Factors associated with khat chewing among high school students in Jimma Town Southwest Ethiopia. J Psychiatry. 2016;19(4):372

48. Abdeta T, Tolessa D, Adorjan K, Abera M. Prevalence, withdrawal symptoms and associated factors of khat chewing among students at Jimma University in Ethiopia. BMC psychiatry. 2017;17(1):142.

49. Lakew A, Tariku B, Deyessa N, Reta Y. Prevalence of catha edulis (khat) chewing and its associated factors among ataye secondary school students in northern shoa, Ethiopia. Adv Appl Sociol. 2014;4(10):225.

50. Gebrehanna E, Berhane Y, Worku A. Khat chewing among Ethiopian University Students-a growing concern. BMC Public Health. 2014:14:1198.

51. Adugna F, Jira C, Molla T. Khat chewing among Agaro secondary school students, Agaro, southwestern Ethiopia. Ethiop Med J. 1994;32(3):161-6.

52. Adere A, Yimer NB, Kumsa H, Liben ML. Determinants of psychoactive substances use among Woldia University students in Northeastern Ethiopia. BMC Res Notes. 2017:10(1):441. 
53. Astatkie A, Demissie M, Berhane Y, Worku A. Prevalence of and factors associated with regular khat chewing among university students in Ethiopia. Subst Abuse Rehabil. 2015;6:41.

54. Kassa A, Loha E, Esaiyas A. Prevalence of khat chewing and its effect on academic performance in Sidama zone, Southern Ethiopia. Afr Health Sci. 2017;17(1):175-85.

\section{Publisher's Note}

Springer Nature remains neutral with regard to jurisdictional claims in published maps and institutional affiliations.
Ready to submit your research? Choose BMC and benefit from:

- fast, convenient online submission

- thorough peer review by experienced researchers in your field

- rapid publication on acceptance

- support for research data, including large and complex data types

- gold Open Access which fosters wider collaboration and increased citations

- maximum visibility for your research: over $100 \mathrm{M}$ website views per year

At BMC, research is always in progress.

Learn more biomedcentral.com/submissions 